\title{
A New Perspective to Reach Out to Children with Special Needs and the Parent Community
}

\author{
Sheela Rajanikanth \\ The Shri Ram School, Vasant Vihar, New Delhi \\ India
}

\begin{abstract}
Full Inclusion though is an ideal academic set-up for Children with Special Needs (CWSN) to get educated; it is time to ponder the effectiveness and benefit of this set up to all the children with special needs. Undoubtedly it is a set-up which helps children with mild learning difficulties to thrive but not for the children with moderate and severe difficulties. Therefore a new perspective for inclusion is given through which not only CWSN get need based education but also their parents get immense support from the school. At present in our school set up we follow an amalgamation of Inclusion- IntegrationRemediation to reach out to maximum number of children with special needs (CWSN) to impart meaningful education. At the same time the parents of CWSN are reached out to share their concerns and issues through pre-set meetings.
\end{abstract}

\section{Scope}

At present, in most of the schools, in the name of full inclusion CWSN are put in mainstream classes but their individual academic needs are not addressed. To address these issues, our school came up with a new model "Inclusion- integration -Remediation which can be explained as follows:

Inclusion is where CWSN are in the mainstream class for all academics and co-curricular activities. These children are in mild to moderate disability category. Integration is one in which the children get education in a small group set up but included with their mainstream peers for all co-curricular activities. These children may fall in category of moderate to severe disability. Remediation is one in which mainstream children with very mild disability get need based remediation from a special educator in the classroom set up or in pulled out sessions. The aim of this model is to reach out to maximum number of children with various disabilities and to provide need based education. By changing the model of inclusion from Full Inclusion to Inclusion - Integration Remediation children with special needs begin to get meaningful education in various set-ups.

By adopting this model, the CWSN who are in inclusive set up get need based input from a special educator. They can be gradually mainstreamed completely and be off SEN.

CWSN who are academically not coping up in class room situation will get academic inputs outside the class room by a special educator in an integrated setup. By doing this we can make them self-reliant in later part of their life.

Similarly the mainstream children with very mild learning disability or specific skill lag can get individualized remediation from a Special Educator without getting the SEN tag. This will help them to put an end to their struggle in class room setup and be confident and thereby become successful in their academic careers.

At present we are catering to children with mild to moderate disabilities. By working further on this model we could extend the support to children with severe disability too.

Also, by extending our support to the emotional needs of the parents, we help them to build a strong and secured CWSN parent community.

If schools all over the world adopt this model we might impart meaningful education to children with various disabilities.

\section{Objectives and Motivation}

The CWSN who are in inclusive set-up get academic input both from mainstream teacher and special educator. Special educator gives need based input in the class itself and do adaptations and accommodations keeping in mind their academic needs.

The children who have moderate learning difficulties and behavioral problems will be at loss if they are in the mainstream class during academic sessions. Hence for them individualized education will be provided in a small set-up keeping in mind their present level of performance. These children spend $40 \%$ of their school time with their peers. This provides social inclusion.

Similarly mainstream children whose difficulties are very mild and skill specific get remediation from special educator without being in SEN.

This way we can reach out to a broad spectrum of children ranging from mild to moderate disabilities with need based education and social inclusion.

Sensitization of school community helped us to strengthen the social inclusion. 
By having a monthly meeting with parents of CWSN the school's primary goal to make the community strong is achieved.

\section{Content as per objective of the paper}

The Shri Ram School, Vasant Vihar started Inclusion in the year 1989. The children with moderately severe difficulties were in mainstream but without any special educator's support. This didn't benefit CWSN since mainstream teachers alone were not able to look into their academic and behavioral needs. Hence we shifted to Learning Centre / Integrated model in 1996. To provide an equal opportunity to CWSN and to participate in all aspects of school life we went back to Full inclusion in 2007 but with special educator's support in the class room. Warnock's intention of inclusion to provide mainstream to the CWSN lost its glory as it has been majorly used as a cost cutting measure in education [1] [2]. However in our school when we reverted back to Full Inclusion we retained the team of special educators, occupational therapist, speech therapist and SENCO as an integral part of the system. Due to failure of our earlier model of Inclusion we re-started inclusion in our school in a step by step manner where children of elementary classes were moved from integrated to inclusive setup in the first year. Later students from Grade II and III were moved to inclusive setup in year 2008. In the following year students from grade IV and V were moved to inclusive set- up. Thus the Learning Centre where integrated education was happening was replaced completely by Full Inclusion in 2009.

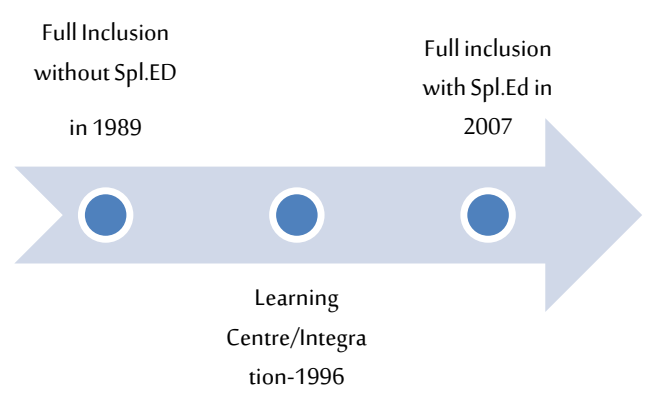

\section{How does it work?}

The children with special needs who are in inclusive set-up get input both from general education teacher and special educator. Special Educator gives need based input in the class and does adaptations and accommodations keeping in mind CWSN's academic needs. All CWSN have an Individualized Education Program (IEP) based on the skills that need to be developed or strengthened. Further implementation of this program is reflected in the monthly work plan. The feedback on their performance is shared with respective parents at the end of every month in the form of a detailed review. Special Educator takes extra classes on Fridays to teach various skills like auditory perceptual skills, visual perceptual skills, organizational skills, and language and communication skills. The students attend these classes after the school hours. This strengthens their skills further.

\section{Challenges faced in Full Inclusion}

While catering to all CWSN in an inclusive set-up we realized that some of them were not getting benefitted by this kind of education. Research study has shown that the education of children with moderate learning difficulties in mainstream schools is generally favorable; however children with severe and complex difficulties and behavioral problems need to be educated in special settings [3]. Hence we brought the following changes in our model.

\section{Table 1. Changes after inception of Full inclusion to} Inclusion-Integration-Remediation model

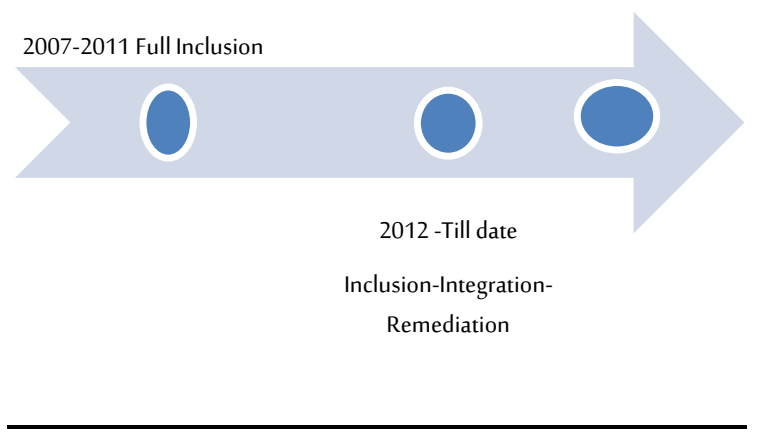

\subsection{Inclusion}

Children with mild and moderate difficulties are getting their education being in mainstream class with special educator's support in the classroom itself.

\subsection{Integration}

After having full inclusion for 3 years we realized that through full inclusion we were unable to impart need based education to each student of ours. Whereas children with highly moderate difficulties and behavioral problems were not able to cope up in the class room situation even after adapting their curriculum completely and also special educator imparting the education in class room. Though physically the student was present in the mainstream class, academically the student was not getting benefit 
by being in the class. Hence we carved out a small setup of integration for these students.This means they attend academic classes in a separate set-up with a special educator; however they attend all activity classes, lunch, assemblies and circle time along with their peers. Thus the social inclusion takes place during these activities. We teach a lot through tailor made life skill program for them.

\subsection{Remediation}

Meanwhile we started identifying mainstream students with specific mild learning difficulties and started remediation program for them. For example if a grade II child has shown difficulties in reading and spelling then a reading program and spelling program have been framed by a special educator. Thus the child whose difficulties are very mild and skill specific gets remediation from special educator without being in Special Education Needs.

\section{Evidences for the success of this model:}

- 2 children who are in inclusive set-up have been shifted to mainstream and they are without the support of special educator.

- The child with Down's syndrome who was struggling hard in inclusive set-up was moved to integrated set-up and has shown tremendous improvement in her academics as she was catered with need based education.

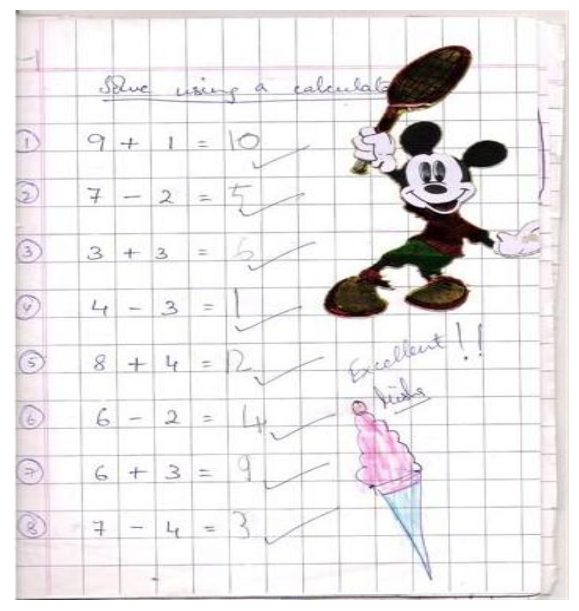

Figure 1. Performance of a child with Down syndrome in an Inclusive set-up

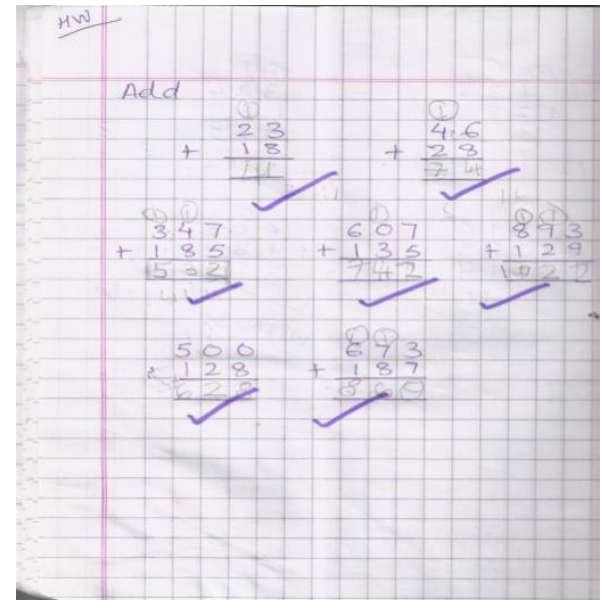

Figure 2: Performance of the same child in integrated setup

- 2 mainstream children with mild learning difficulties who got remediation from special educator for a period of 2 years were shifted to mainstream completely without special educator's support.

\section{Reaching Out to the Parent Community:}

In 2009, we started monthly meetings called Rainbow Smile Meeting (RSM) to reach out to the community. The reason behind starting this is to provide a platform for them to share their fear, concerns and thereby to bond among themselves. It started with the intention of bonding time for parents but it also resulted in making them to feel comfortable to share the newly learnt techniques. Parents of CWSN congregate every month in the school, Special Needs Coordinator (SENCO) and special educators act as facilitators for these meetings.

While doing so we felt the need to support the emotional turmoil they are undergoing as parents of CWSN. Hence we started in 2012 a bimonthly session, 'Caring for Carers' (CFC) with a competent counselor. This interactive session with counselor addresses various growing up issues and other aspects of parenting of CWSN.

The CFC meetings brought a lot of changes in the outlook of parent community and thus it helped the CWSN to be accepted.

\section{Impact of RSM and CFC on Inclusion:}

1) The school has learnt the problems of the parents and been working to solve them.

2) Parents who were emotionally wrecked now have got confidence and started enjoying the process of parenthood.

3) Bonding amongst the parent community has thickened. 
4) Through CFC, the school solved various issues and trained the parents.

5) Parents have been empowered to teach their children various skills like Fine Motor activities, Gross Motor activities, Math in daily life, Life skills etc.

\section{Sensitization Program}

Every academic year begins with sensitization activities like role play, puppet show and hands on activities. Special educator along with General Ed teacher takes it up based on the conditions of CWSN, difficulties they are facing etc.

Sensitization is carried out with various communities associated with the school to build a sensitive community.

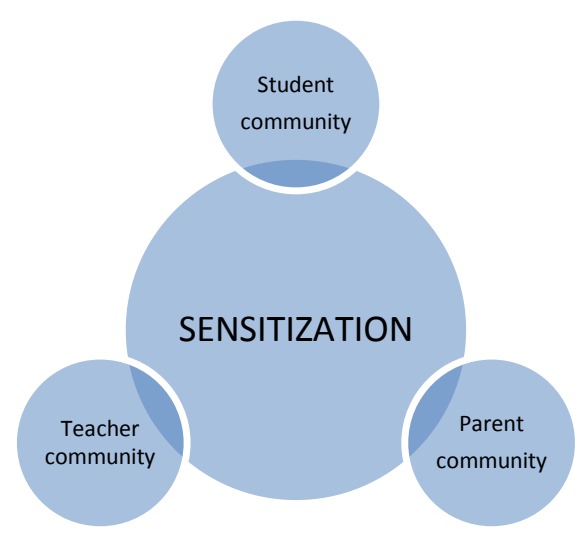

\section{Factors contributing to the success of the model:}

1) Individualized attention is given to each child by maintaining the ratio of special educator to CWSN as $1: 3$ to $1: 5$ based on the difficulties of the children.

2) Highly skilled special educators and providing time to time professional training to them has helped in updating their knowledge.

3) Continuous sensitization program is being conducted across the school by special educators and class teachers to build a sensitive community.

4) Rainbow Smile Meeting, for the CWSN parents to put across their concerns, feedback has helped to evolve a better system of education.

5) 'Caring for Carers' has helped in settling emotional needs of parents.

\section{Impact of Integration and Remediation on Inclusion:}

1) Starting integrated setup helped the special educator in the inclusive setup to concentrate more on the CWSN in the mainstream class. Hence the performance levels of these students have improved tremendously.

2) Special educators in inclusive setup started getting more teaching time per child as compared to earlier setup.

3) Children in integrated setup are becoming more confident socially and academically as they do not feel left out during their academic classes.

4) Children in integrated set up are getting structured education through Open Basic Education system.

5) Mainstream children who are getting remediation from the special educators are performing much better. In 2 cases we have withdrawn the remediation support as their performance is at par with their peers.

\section{Outcome of Inclusion}

- After following the above model we could mainstream 2 children completely. Mainstreaming a child means they are in the class without any support from special educator. The mainstreaming is done in a graded manner i.e. taking one subject at a time. Once a CWSN is performing very well he is being weaned off from special educator's input. In duration of 2 years the child is completely mainstreamed.

- Children with special needs who are in integrated setup have grown in self-confidence.

- Mainstream children have become sensitive to the needs of these children and reach out to them whenever needed.

- General Education teachers have understood CWSNs needs and support them academically as well as emotionally.

- Gen Ed teacher's role has changed from $60 \%$ partnership to almost $100 \%$ active participation in imparting skills to CWSN in class room.

- The parent community has accepted the inclusiveness so well that when we started giving admission to children from Economically Weaker Section in inclusive setup they started need based educational program for them.

\section{Challenges faced}

- As the rate of influx of Gen. Education teachers per year is high, training them to adapt their teaching techniques to our setup is still a challenge. 
Table 2: Comparative study between various models of education imparted for CWSN in The Shri Ram School:

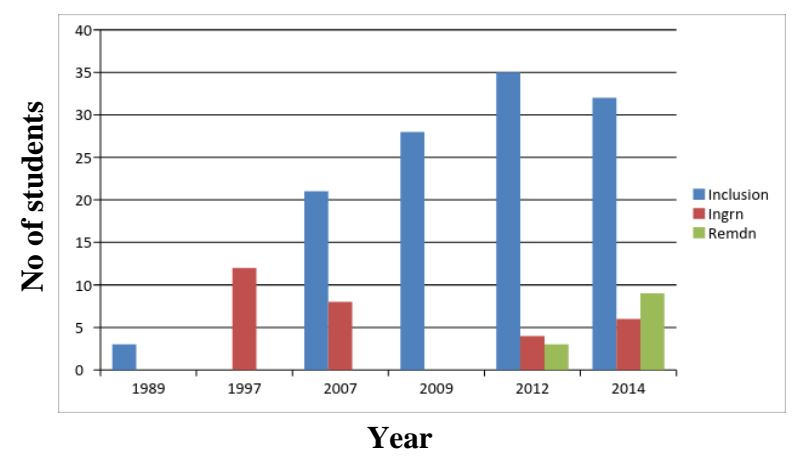

The graphical analysis of data of CWSN in various set up in the transition years and the present day situation clearly depicts

1) Reaching out to more CWSN is possible due to this model when compared to the earlier ones.

2) CWSN started getting academic inputs in different set-ups based on their academic needs.

\section{Conclusion}

The Inclusive Education program that The Shri Ram School started way back in 1989 has seen a lot of changes as it have reached out to a broader spectrum of children ranging from very mild to moderate disabilities. By providing need based education our ultimate goal is to make the children with special needs self-reliant in their lives.

Our research study taught us that there is no single model of education which is perfect for the children with special needs. However through a combination of models like inclusion, integration and remediation we have helped the children to get the right kind of education.

Also, by extending our support to the emotional needs of the parents, we have helped them to build a strong and secured CWSN parent community.

\section{Acknowledgement}

This project was supported by The Shri Ram School Vasant Vihar.

I thank Nandini Rao, AUA, Antigua for her insightful critics and advise during the preparation of the manuscript.

\section{References}

[1] John MacBeath, Maurice Galton, Susan Steward, Andrea MacBeath and Charlotte Page; The Cost of Inclusion, University of Cambridge, Faculty of Education: 2006; (1-60).

[2] DES [Department of Education and Science] (1978) Warnock Committee Report, London: HMSO.
[3] Simon Ellis, Professor Janet Todd, Lynne GrahamMatheson; Special Education Needs and Inclusion, NASUWT: 2008; (1-113) 